Competitive Supply Chains 



\section{Competitive Supply Chains}

A Value-Based Management Perspective

2nd edition

Enver Yücesan

INSEAD, France 


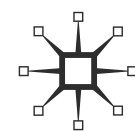

(c) Enver Yücesan 2007, 2016

Softcover reprint of the hardcover 2nd edition 2016 978-1-137-53265-7

All rights reserved. No reproduction, copy or transmission of this publication may be made without written permission.

No portion of this publication may be reproduced, copied or transmitted save with written permission or in accordance with the provisions of the Copyright, Designs and Patents Act 1988, or under the terms of any licence permitting limited copying issued by the Copyright Licensing Agency, Saffron House, 6-10 Kirby Street, London EC1N 8TS.

Any person who does any unauthorized act in relation to this publication may be liable to criminal prosecution and civil claims for damages.

The author has asserted his rights to be identified as the author of this work in accordance with the Copyright, Designs and Patents Act 1988.

First published 2007

This edition published 2016 by

PALGRAVE MACMILLAN

Palgrave Macmillan in the UK is an imprint of Macmillan Publishers Limited, registered in England, company number 785998, of Houndmills, Basingstoke, Hampshire RG21 6XS.

Palgrave Macmillan in the US is a division of St Martin's Press LLC, 175 Fifth Avenue, New York, NY 10010.

Palgrave Macmillan is the global academic imprint of the above companies and has companies and representatives throughout the world.

Palgrave ${ }^{\circledR}$ and Macmillan ${ }^{\circledR}$ are registered trademarks in the United States, the United Kingdom, Europe and other countries.

ISBN 978-1-349-55679-3 ISBN 978-1-137-53267-1 (eBook)

DOI 10.1057/9781137532671

This book is printed on paper suitable for recycling and made from fully managed and sustained forest sources. Logging, pulping and manufacturing processes are expected to conform to the environmental regulations of the country of origin.

A catalogue record for this book is available from the British Library.

A catalog record for this book is available from the Library of Congress.

Typeset by MPS Limited, Chennai, India. 
To the loving memory of my dear mother, Dr. Mürüvvet Aydin Yücesan 



\section{Contents}

List of Figures and Tables viii

Preface $\quad x i$

Introduction: End-to-End Supply Chain Design 1

1 Working Definitions 11

2 Value-Based Management: The Guiding Principle for SCM 24

3 Value Creation: Dynamic Supply Chain Design 38

4 Value Creation: Assessing the Cost-Service Trade-off 67

5 Value Capture: Aligning Supply Chain Partners 91

6 Impact of Technology on SCM: A Brief History of IT for SCM 116

7 Service Supply Chains 135

8 Concluding Comments 149

$\begin{array}{ll}\text { Appendix } & 157\end{array}$

$\begin{array}{ll}\text { Notes } & 159\end{array}$

$\begin{array}{ll}\text { References } & 162\end{array}$

$\begin{array}{ll}\text { Index } & 165\end{array}$ 


\section{List of Figures and Tables}

\section{Figures}

P.1 Value-based SCM framework for Coloplast xiii

P.2 Modeling approaches used in the book xiv

I.1 Global seeds market 3

I.2 Demand-supply mismatch costs 5

$\begin{array}{lll}\text { I.3 The R\&D cycle } & 6\end{array}$

$\begin{array}{lll}\text { I.4 Field production in the northern hemisphere } & 7\end{array}$

I.5 Generation of a production, processing, $\begin{array}{ll}\text { and distribution plan } & 7\end{array}$

I.6 Seed processing 8

$\begin{array}{llr}\text { I.7 Forecast volatility } & 9\end{array}$

$\begin{array}{ll}\text { I.8 Summary of key planning steps } & 10\end{array}$

1.1 Manufacturing as the locomotive of growth 12

$\begin{array}{lll}1.2 & \text { Top manufacturers around the globe } & 13\end{array}$

$\begin{array}{lll}1.3 & \text { Global technologies and innovators } & 14\end{array}$

$\begin{array}{lll}1.4 & \text { Labor-intensive tradables } & 15\end{array}$

$\begin{array}{lll}1.5 & \text { Global trade routes (1990-2010) } & 16\end{array}$

1.6 Defining value as [willingness-to-pay - cost] 18

1.7 The interaction between value creation and value capture 18

$\begin{array}{ll}1.8 \text { Working definition of a supply chain } & 19\end{array}$

1.9 Matching demand and supply in a supply chain 21

2.1 Value-based management as the guiding principle for SCM 25

2.2 Cascading EP across the organization 31

2.3 Creating value by higher capital turns 32

2.4 Deploying the invested capital 33

2.5 The operating cycle 33

2.6 Economic profit in SCM 36

3.1 Xerox's European distribution network in 1990s 39

3.2 Vertical industry structure and integral product architecture in the computer industry, 1975-1985 40

3.3 Vertical industry structure and integral product architecture in the computer industry, 1985-1995 40

3.4 Fine's double Helix model of industry evolution 42

3.5 The rhythm of development activity in the electronics
industry (Mendelson and Pillai 1999) 
3.6 Product life cycle compression: 1988-1995 (Mendelson and Pillai 1999)

3.7 SCM drivers of value from a SCOR perspective 46

3.8 Supply chain design 46

3.9 The LP formulation for network configuration 48

3.10 Three-dimensional concurrent engineering (Fine 1999) 50

3.11 Mapping for organizational, technology, and capability chains

3.12 Value-based supply chain management 58

$\begin{array}{ll}3.13 \text { Globalizing ecosystems } & 59\end{array}$

$\begin{array}{ll}3.14 & \text { Distribution of disasters over time } \\ 3.15 & 59\end{array}$

$\begin{array}{ll}3.15 & \text { Monitoring corporate social responsibility }\end{array}$

3.16 Risk management framework $\quad 63$

3.17 The risk matrix $\quad 65$

4.1 A simple supply chain 69

4.2 A base stock inventory system 70

4.3 The cost-service trade-off curve for HP deskjet printers $\quad 75$

4.4 The impact of seasonal demand for toys: seasonal stocks $\quad 81$

4.5 Cycle stocks and the economic order quantity 82

4.6 Coordinating production and assembly through decoupling stocks 84

4.7 Working capital of various agri-business companies 86

$\begin{array}{lll}4.8 & \text { Supplier financing } & 89\end{array}$

5.1 The bullwhip phenomenon 92

5.2 An integrated production-distribution system 98

5.3 Decision tree for the Newsvendor problem 100

5.4 A decentralized production-distribution system 101

5.5 Decision tree for the retailer 101

5.6 A decentralized production-distribution system with buyback 103

5.7 Decision tree for the retailer 105

5.8 Emerging markets for pharmaceuticals (Huybrecht et al., 2012)

5.9 Strategic outsourcing in the pharmaceutical supply chain

6.1 Upton and McAfee's framework for electronic connectivity

6.2 Canceling an order in the three-tier client-server architecture $\quad 126$

6.3 SAP's HANA platform $\quad 127$

6.4 Business-to-business digital transaction models 128 
6.5 Kaplan and Sawhney's B2B trading matrix

6.6 Reach versus richness trade-off in supplier certification

7.1 Evolution of different sectors in a developed economy

7.2 The product-process matrix

7.3 Service-intensity matrix

7.4 Waiting for an elevator

7.5 Interfacing the front office and the back office for CIBA vision

7.6 The Eurologistics solution

7.7 Managing capacity at Lufthansa (Huchzermeier, '02) 147

8.1 Major initiatives along the supply chain

8.2 HP's BDD supply chain in mid-1990s

8.3 HP's customer orientation

8.4 Material, information, and cash flows 152

8.5 The new HP supply chain 153

8.6 Planting rice 154

8.7 The Tegra offer 154

8.8 Bottle blowing 156

\section{Tables}

2.1 WCR for 1,000 large European corporations 35

2.2 Operational drivers of economic profit 35

3.1 Product offerings of leading mountain bike manufacturers $\quad 51$

3.2 Characteristics of functional vs. innovative products 52

3.3 Supply chain characteristics 52

3.4 The matrix of organizational dependency and product modularity $\quad 55$

4.1 Drivers of inventory $\quad 86$

$\begin{array}{lll}5.1 & \text { Supply chain costs } & 107\end{array}$

$\begin{array}{ll}5.2 \text { Characteristics of the supply base } & 108\end{array}$

$\begin{array}{ll}5.3 \text { Channel relationships } & 109\end{array}$

5.4 Logistics services 110

5.5 Process characteristics 110

5.6 New requirements in pharmaceuticals 113

6.1 Key trends in supply chain management (Top 12 of 22) 119

6.2 Shortcomings of current ERP systems for SCM 123

7.1 Product and service characteristics 136 


\section{Preface}

It is generally accepted that Supply Chain Management (SCM) started gathering steam in the early 1990s when a Kurt Solomon and Associates study concluded that the demand-supply mismatches were costing the US grocery industry $\$ 30$ billion a year. ${ }^{1}$ Up until then, SCM was considered to be an obscure back office activity, typically labeled as "warehousing and distribution" or, a bit more gloriously, "logistics." A ruthless wake-up call, $\$ 30$ billion represents a shocking number when one realizes that low-margin products such as toothpaste, broccoli, and flour are at stake in this industry. On the one hand, keeping additional stock to provide high levels of customer service is risky in this setting due to enormous variety in products and their short shelf-life. On the other hand, stock-outs, which are typically around $7 \%$ of sales for better managed companies, lead to lost sales not only for the grocery store but ultimately for the overall industry, including the retailer and the manufacturer, should the customer abandon the purchase altogether. It was quickly discovered that other industries were also facing similar challenges. Under such difficult circumstances, many industries have undertaken revolutionary initiatives in streamlining their go-to-market strategies. Over the past decade, a flurry of research, development, and deployment has transformed SCM into a mature discipline in its own right.

Within that period, numerous books and thousands of articles have appeared on the topic, contributing to the rapid advancement of the field. However, two gaps in the literature still persist. First, activities within the realm of SCM are typically viewed as cost centers, whereby cost minimization remains the key focus of most SCM streamlining efforts. To compound the problem, the divide between the performance metrics typically used in the trenches (such as inventory turns, order fulfillment rates, and order turnaround times) and the financial indicators typically monitored by the upper management and the investors (such as economic profit, return on invested capital (ROIC), and return on net assets (RONA)) remains wide. This book adopts a value-based management (VBM) perspective, in which SCM's key mission is value creation and capture. SCM solutions are developed and deployed to create value for everyone who comes into contact with a company's products and services. In this setting, "value" could be created by simply minimizing costs. On the other hand, there are situations in which 
cost minimization simply destroys value for the stakeholders, necessitating alternative strategies. VBM therefore enables the adoption of a wider business perspective for SCM. Furthermore, such a perspective also allows us to map operational performance metrics to the financial performance indicators in a straightforward fashion, enabling the evaluation of whether or not the proposed supply chain solutions are ultimately value enhancing or value destroying.

While necessary, value creation, however, is not sufficient for value capture. There are many examples in which an innovative design introduced by one company has been successfully commercialized by another, leaving the original inventor with little profits. This, in turn, brings us to the second gap in the literature based on the popular adage that "competition is no longer between companies but between supply chains." Implicit in this statement is the assumption that modern supply chains operate as a single well-coordinated entity, like a basketball team, with a clearly defined command-and-control structures. This might have been true in the early 20th century where many industries exhibited full vertical integration. Today's supply chains, however, are ecosystems, with no clear governance-or command-andcontrol structure, consisting of independent organizations. As these "economically rational agents" interact with each other, there might be serious misalignments within the ecosystem due to diverging local priorities, which might hinder the performance of the overall supply chain. In other words, having a star player in each position does not necessarily guarantee victory as a team. The performance of the Dream Team representing the United States at the 2006 World Basketball Championships in Japan is a relevant benchmark for modern SCM. In many industries ranging from personal computers to airlines, different supply chain members display widely different profitability levels. This book therefore adopts a decentralized view of the supply chain and puts an emphasis on economic mechanisms to promote coordination and collaboration within this ecosystem, so that the value created by the supply chain is captured in an equitable fashion by all its members. In other words, we would not only like our basketball team to win but also make sure that all the players are recognized—and rewarded—for their contribution to the team effort.

Finally, it is important to realize that the supply chain solution, which achieves the desired targets in value creation and value capture, is necessarily temporary. As products have expiration dates and as processes become obsolete, supply chain solutions also have limited shelf lives. Changes in competitive forces, in customer preferences, in technology, 
and even in legislature may render the existing supply chain solution inadequate. One must therefore keep an eye on these key drivers and not hesitate to go back to the drawing board when the existing supply chain solution can no longer support the changing business strategy. After all, supply chains deploy an organization's go-to-market strategy. As that strategy evolves, the supply chain solution must evolve with it.

Another novelty embodied in this book is the framework through which the material is presented. This framework is summarized in Figure P.1. The horizontal axis represents the scope of the book. It starts with a vision: VBM, the challenge of providing value to anyone who comes in contact with a company's products and services. This vision is operationalized through strategy formulation, which defines the company's business model, its affinity for product and process innovation, and its investment in developing and acquiring resources. The strategy is then deployed through key processes that are at the heart of supply chain management. These processes represent the concrete enablers of VBM. The focus is then on deployment with an explicit discussion of the technologies, structures, and skills required for the roll-out of effective supply chain solutions. The adoption of such a broad scope has a dual purpose. First, we wish to draw the attention of top decisionmakers to the strategic role of SCM in value creation and capture, and put SCM on the CEO's agenda. Conversely, we would like to broaden the

\begin{tabular}{|c|c|c|c|}
\hline & Vision & Strategy & Enablers \\
\hline Context & VBM & $\begin{array}{l}\text { Innovation } \\
\text { Resources } \\
\text { People }\end{array}$ & $\begin{array}{l}\text { Go to market } \\
\text { Key processes } \\
\text { Technology } \\
\text { Deployment } \\
\text { Performance } \\
\text { management }\end{array}$ \\
\hline Illustration & $\begin{array}{l}\text { Better } \\
\text { quality of } \\
\text { life }\end{array}$ & $\begin{array}{l}\text { Product and } \\
\text { process } \\
\text { innovation, } \\
\text { product }\end{array}$ & $\begin{array}{l}\text { Accelerate ideas } \\
\text { to market, } \\
\text { closed loop } \\
\text { distribution }\end{array}$ \\
\hline \multicolumn{2}{|c|}{ Technicalities } & \multicolumn{2}{|c|}{$\begin{array}{l}\text { Multiple sourcing, } \\
\text { Cross-functional development } \\
\text { Centralized planning and } \\
\text { scheduling }\end{array}$} \\
\hline
\end{tabular}

Figure P.1 Value-based SCM framework for Coloplast 
perspective of supply chain professionals by demonstrating explicitly the contributions they make to the firm's overall strategy through the initiatives they undertake in designing, coordinating, and managing supply chains.

The vertical axis represents the scale of the book. It starts with the motivation by establishing the context of the problem to be addressed. An illustration in the form of a mini case study is then provided to render the discussion concrete. It is worth emphasizing that these illustrations will not come from frequently cited (and often abused) examples, but from companies such as ASML, Coloplast, CIBA Vision, PSA, PPR, Firmenich, Nissan, Syngenta, and Mattel, all best-in-class examples deserving broader exposure. Finally, we not only present alternative solutions to the problem at hand but also provide the technical details through models that provide the basis of the proposed solution. Such an approach guarantees both the relevance of the topics addressed in this book and the rigor underlying the proposed supply chain solution. The wide range of models we will use throughout this book is listed in Figure P.2. While models are necessarily simplifications of reality that allow us to focus on the key parameters of the decision at hand, they have one big advantage: they enable clear articulation of all the assumptions made in building the model. The discussion should then focus on the validation of those assumptions. Once this is done, models provide us with an objective platform for conducting our analysis. We have, however, paid particular attention so that the technical developments throughout the text do not distract attention from the main discussion.

\begin{tabular}{|l|l|}
\hline Model & Application \\
\hline Little's Law & Pipeline inventory \\
\hline EOQ (Wilson) & Batch sizing \\
\hline Newsvendor & $\begin{array}{l}\text { Safety stocks } \\
\text { Supply chain coordination/contracting }\end{array}$ \\
\hline Base stock policies & Cost-service trade-off \\
\hline \multicolumn{1}{c}{ - Loss function } & Expected lost sales \\
\hline Linear programming & Supply chain configuration \\
\hline Queueing & Service systems, capacity management \\
\hline Poisson process & Failure events/rare events \\
\hline Free cash flow & Value definition and cascading \\
\hline
\end{tabular}

Figure P.2 Modeling approaches used in the book 
Hence, the reader can enter into the technicalities only when he/she feels necessary to do so.

Figure P.1 is an illustration from Coloplast, a Danish wound care company, whose vision is to be the preferred source of medical devices and associated services contributing to a better quality of life. Coloplast operationalizes this vision through innovation both in products (which provide improved functionality, hence higher comfort levels, to patients) and in processes (which develops not only efficient manufacturing capabilities but also an agile supply chain for quick deliveries). To this end, processes have been put in place to accelerate new product development and market introduction as well as to have a balanced product distribution on a global scale. All of these processes are based on sound materials management principles.

Introduction in this book is meant to provide the reader with a sneak preview of the topics that will be further developed in the book. It describes the end-to-end supply chain design challenges in agri-business with the aim of painting the big picture before drilling down into its many fascinating facets.

Chapter 1 makes the case for supply chain management as an enabler to deploy and execute an organization's go-to-market strategy. It also furnishes some of the working definitions.

Chapter 2 offers a concise definition of "value" from a financial perspective. Operational drivers of "value" are then determined with the objective of identifying those SCM initiatives that contribute to the value creation challenge of an organization. Chapter 3 then focuses on value creation by emphasizing the product, process, and supply chain design in a concurrent fashion. In particular, we emphasize the temporary nature of competitive advantage and the resulting necessity of continuously developing new supply chain solutions in the face of a constantly evolving competitive landscape. Many value-creating initiatives, however, entail a cost-service trade-off. To assess the magnitude of this trade-off, Chapter 4 introduces a materials management model. This model can be deployed not only to guide the positioning of a company's goods or services in the short run, but also to assess the impact of investments in new product, process, and supply chain design in the long run to mitigate the cost-service trade-off.

Chapter 5 focuses on value capture. In particular, it describes both short-term and long-term initiatives to encourage collaboration in a decentralized supply chain. SCM is an information-intensive discipline. Chapter 6 therefore summarizes the impact of information and communication technologies (ICTs) on SCM practices; it also highlights the 
enhancing role of emerging technologies in SCM. Just like products, services are also conceived, produced, and delivered through supply chains. There are nevertheless significant differences between product and service supply chains. These differences are discussed in Chapter 7 along with guidelines of coordinating the two types of ecosystems. Chapter 8 offers some concluding comments.

A television advertisement for UPS at the height of the dot-com boom clearly showed the importance of effective supply chain strategies. The advertisement starts with a group of young entrepreneurs sitting in front of a computer terminal and counting down for the launch of their new web-based business. Once they go live, they start waiting for customer orders. The first customer order, signaled with a "bing" on their computer, is greeted with a wild cheer by all the entrepreneurs. The cheers grow wilder as the second, the fifth, the tenth, and the fiftieth order trickles in. However, as the trickling soon turns into a shower of orders, which cross the threshold of the thousandth customer order, their cheer quickly turns into deep anxiety: how are they going to deliver all these orders? This book therefore adopts the perspective that SCM should be viewed as the effective deployment of value-based business strategies.

\section{Changes in the second edition}

Supply chain management is a dynamic field where we are faced with new challenges and opportunities every day. The additions to the second edition reflect some of the key developments that have taken place since 2007. In particular, I start the book with an end-to-end supply chain design scenario that provides the reader with an overview of the challenges that will be addressed in detail later in the book. I have updated our statistics. I also have a crisper discussion on the operational drivers of value, one of the key pillars of our discussion. I have incorporated new topics such as risk management, contracting in the early stages of a product's life cycle, and corporate social responsibility. I offer many new illustrations and examples that have been generated through repeated interactions with numerous supply chain professionals. I would like to thank them for making me part of their supply chain journey. Let me conclude by thanking Ms. Liz Barlow, who rekindled this project. 